\title{
The Leaf-skin Theory of the Stem: A Consideration of certain Anatomico-physiological Relations in the Spermophyte Shoot.
}

\author{
BY \\ EDITH R. SAUNDERS, \\ Fellow of Nerwham College, Cambridge.
}

With thirty-four Figures in the Text.

I. INTRODUCTION.

(i) THE original problem and the wider question which arose out of it.

1 In the course of investigations upon the inheritance of hairiness in Matthiola incana, necessitating examination of the young plant from the moment at which the plumule becomes visible, one cannot but be struck with the remarkably sharp line of demarcation, occurring at the cotyledon node, between the completely glabrous hypocotyl and the felt-covered plumule (see Fig. 1). As the shoot elongates it becomes apparent that the epicotyl axis is thickly covered with hairs as well as the foliage leaves, while the now fully developed cotyledons and hypocotyl remain glabrous (see Fig. 2). Confronted year after year with this sharp contrast one was inevitably led to speculate as to its cause. A study of many Spermophyte seedlings has brought to light certain anatomical and physiological relations which appear not only to furnish a clue to the different character of the axis above and below the cotyledon node, so conspicuous in many species besides the Stock, but to throw light on the nature of the shoot axis in general.

(ii) The nature of the evidence. The observations from which the conclusions set forth below are derived are concerned almost wholly with the surface anatomy of the plant. They deal with relations some of which have been recognized and find mention in detailed systematic descriptions, although no particular significance seems to have been attached to them. Others, on the contrary, do not appear to have been noticed. Regarded by themselves and apart from all other considerations the anatomical features

1 A brief preliminary communication on this subject was made at the Meeting of the British Association for the Advancement of Science in I92I. The present account covers a much wider field of observation, and the application of the leaf-skin conception is considerably extended.

[Annals of Botany, Vo1. XXXVI. No. CXLII. April, r922.] 


\section{36 Saunders.-The Leaf-skin Theory of the Stem:}

here described will seem, no doubt, trivial in character, but viewed in the light of their relation to the plan of construction as a whole they assume a new importance and call for some explanation capable of general application. The sought-for solution, simple and obvious when once the facts have been grasped, is to be found in a definite (? universal) downward extension of the leaf area below the node level.

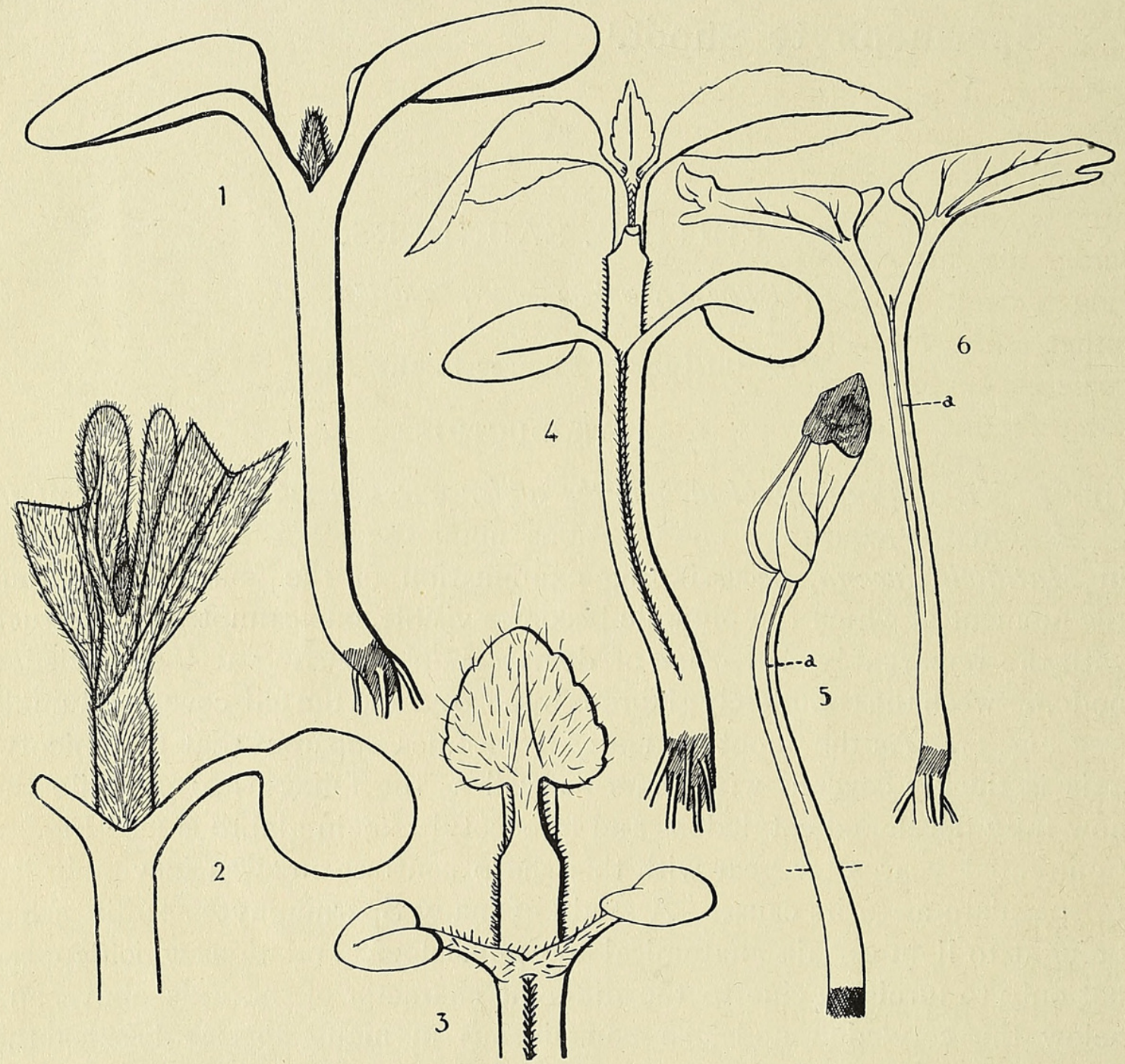

Figs. I-6. I, Matthiola incana, seedling showing glabrous cotyledons and hypocotyl and hairy plumule. 2, older stage (lower leaf-tips removed). 3, Veronica hederaefolia, seedling; hypocotyl with a line of hairs along the potential edges of the cotyledon extensions. 4, Lopezia coronata, seedling plant; hypocotyl and internodes showing the same feature. 5 , Ipomoea sanguinea, young seedling; $a$, the furrow formed between the edges of the cotyledon extensions. 6 , older stage of the same.

\section{General Statement of the Facts and Consideration OF THEIR SigNifiCANCE.}

To return for a moment to the case of the Stock. It will be admitted that the absence of hairs from the cotyledons of a hairy-leaved form cannot be supposed to be entirely the result of an intra-seminal environment, since in some types the surface of the cotyledons is seen to be covered with hairs immediately they become free of the seed-coat. We need, therefore, to 
look for some other explanation. Now it is to be observed that in some species the margins of the cotyledons become confluent at the level of insertion, completely enveloping the axis and forming a sort of cup or socket out of which the plumule emerges. This condition was found to exist in a very large number of the Dicotyledons examined and in several of the Gymnosperms. Where the cotyledons are of considerable thickness; as e.g. in Gorse (Ulex europaea) and Stock (Matthiola incana), the socket rim may be quite substantial (see Fig. I); where they are less solid in structure it is correspondingly thinner. In the former case the hypocotyl has the same appearance all round and is usually featureless, but in certain species coming under the latter head a distinct ridge or welt may be traced down either side from the point of coalescence of the cotyledons towards the root, as in Rivina humilis, ${ }^{1}$ Plum. (Phytolaccaceae) (see Fig. 9). Or in place of a ridge there may be a well-defined line of hairs such as is seen under certain conditions in Veronica hederaefolia and Lopezia coronata (see Figs. 3 and 4), or, again, the two characters may coexist. Thus in Ruellia amoena the ridge is ordinarily surmounted by a conspicuous line of characteristically shaped hairs, the rest of the surface being glabrous (see Fig. 7). When the seedling is growing under conditions which

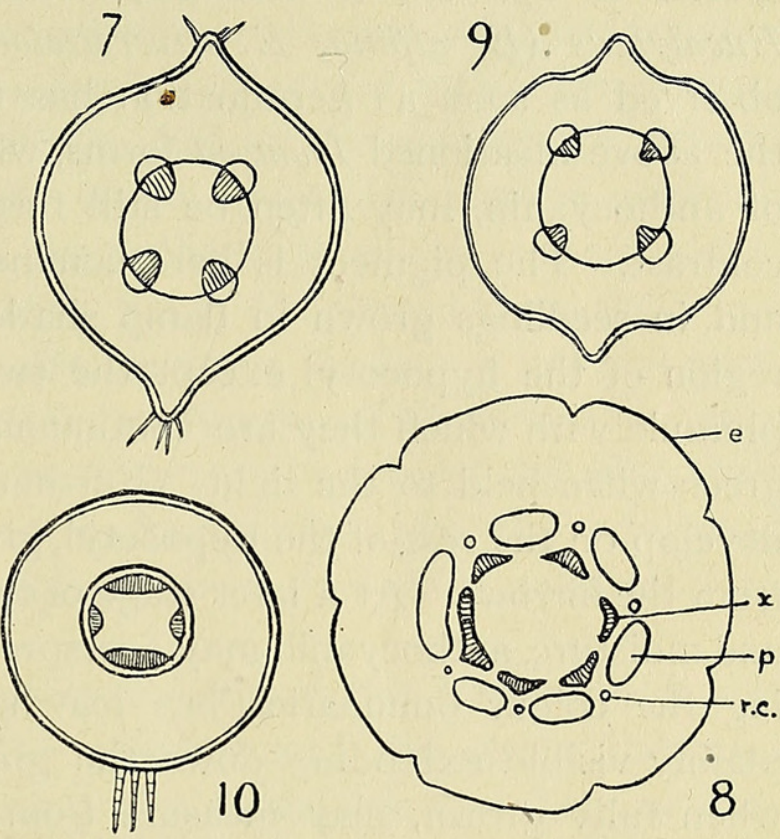

Figs. 7-IO. 7, Ruellia amoena, hypocotyl in transverse section; the potential ed ges of the cotyledon extensions are thrown up into a ridge surmounted by hairs. 8, Pinus maritima, hypocotyl (after Chauveaud). e., epidermis; $x$., xylem; $p .$, phloem ; r.c., resin canal. 9, Rivina humilis, hypocotyl showing the same feature as Ruellia but without the hairs; the shallow groove on either side of the ridge results from the angled form of the cotyledon petioles. I $\circ$, Stellaria media, internode in transverse section. are still more favourable to hair formation the hairiness may, however, become general, and in the same way Rivina, in which the ridge is more often glabrous, will sometimes develop a hair line under altered conditions. In the Polygonaceae the coalescence is emphasized by the production of a tubular sheath extending upwards for a short distance above the node level. In

1 The presence in Rivina of a shallow furrow on either side of the ridge, indicated in the transverse section but more clearly seen in a surface view of the seedling, might suggest at first sight that this type should be classed with Eucalyptus and Ipomoea (see later). But the furrows in this plant have a different origin. A close examination shows that they are not intercotyledonary, but arise through a foreshadowing in the cotyledon stalk at its insertion of that four-angled shape which is assumed by the petiole of the leaves. 
certain Gymnosperms several alternate ridges and furrows are visible in the hypocotyl, corresponding in number to the cotyledons, as e.g. in Pinus maritima (see Fig. 8) and Picea orientalis, Carr. We may place in another and probably much smaller category those species in which the width of the cotyledon insertion just falls short of half the circumference of the axis, so that the hypocotyl is not completely embraced. The result is a double contour line on each side extending down from the adjacent cotyledon edges and bounding a narrow longitucinal interspace which is seen as a slight furrow. This condition is well illustrated in species of Ipomoea (I. coccinea, I. sanguinea (see Figs. 5 and 6)) and Eucalyptus.(E. alpina, E. diversicolor, E. gomphocephala), and can be observed as soon as germination has taken place. The contour lines in the above-mentioned Ipomoea forms, which contain a considerable amount of anthocyanin, may often be still further accentuated by a sharp colour contrast. The pigment is here confined to the first sub-epidermal layer, and in seedlings grown in damp shade it may colour the whole exposed region of the hypocotyl except the two furrows, which, together with the plumule with which they are continuous, appear of a beautiful translucent green when held to the light. Furthermore, the epidermal papillae which develop on the rest of the hypocotyl, giving it a pile-like surface, are absent from the furrows. At a later stage or under other conditions of illumination and moisture, anthocyanin may overspread these intervening strips, obliterating the colour boundaries but leaving the structural contour lines still plainly visible extending down the greater part of the hypocotyl, which, when fully grown, may measure from $I_{2} \frac{1}{2}$ to 2 inches in length. These shallow furrows, which are separated from the vascular ring by several layers of cortex, cannot be causally connected with any internal tissue distribution. Rather we are led by the facts adduced to regard ridge, furrow, hair line, and colour boundary as marking the limits in the superficial tissue of areas which are composed of downward extensions of the cotyledons between which, when the contours are double, appear similar prolongations of the next leaf-pair. In other words, this superficial tissue, i. e. the epidermis and one layer at least of the hypoderm (and possibly deeper layers as well), must be considered, so long as it is desirable and practicable to maintain this distinction, as foliar and not axial in nature. We can then look upon Ipomoea, Lopezia, and Ulex as representing gradations in a series of stages passing from a condition in which the cotyledon-extension edges are actual, ${ }^{1}$ defined by anatomical and in certain circumstances by colour boundaries in addition : through that in which there is fusion of the contiguous margins, but a fusion of so superficial a character that the lines of junction exhibit features which we associate with potential

1 In the sense that they are separate from each other although the whole extension is completely confluent with the axis. 
edges : to one in which the union is sufficiently deep or so exactly adjusted that no anatomical demarcation is traceable. But though in this last case the boundaries are uncharted and signposts are wanting, we may safely presume that the development of the cotyledons follows the same course as in the two other types. When the potential edges are not only fused but become thrown out into ridges the explanation may be that growth in circumference in the cotyledons is more rapid than in the axial core, and that accommodation takes place in this way, while the condition in which the edges become actual may arise through the initial increase being greater in the core than in the cotyledons.

Now it is a familiar fact that anthocyanin production and hair formation are both characters which vary considerably in accord with environmental conditions. We may find, for example, that an Ipomoea grown exposed to full sunlight in dry soil has the entire hypocotyl surface uniformly coloured; or again, that some Veronica individuals will show a completely glabrous hypocotyl, while others have hairs distributed over the whole surface. But the important point which concerns us here is not that under certain conditions hairs and anthocyanin can overspread the entire area, or on the other hand that their formation can be entirely suppressed, but that, under the appropriate conditions, the disposition of hairs, colour, or other anatomical features always follows a certain definite arrangement in relation to the morphological ground-plan.

But if this view of the composite nature of the hypocotyl is well founded, are we to conceive of the epicotyl and the shoot thereafter produced from it as likewise consisting of a foliar skin enclosing an axial core? A careful examination of the stem surface shows that precisely similar and equally plain evidence is obtainable from the later developed as from the seedling shoot, the foliage-leaf extension being clearly outlined in many species by a furrow or ridge, or by a hair or colour line. And further, that where these topographical features are present they stand in a direct relation to (I) the general orientation of the individual, (2) the mode of phyllotaxis, (3) the proportion of the circumference of the axis occupied by the leaf-insertion. For example, if, in a species exhibiting one or other of these features, the leaf arrangement is decussate with a leafinsertion width of half the stem circumference, then the congenitally fused but potential edges of the foliar extensions will show two longitudinal boundary or fusion lines in each internode, extending from the points where the free portions of each leaf-pair come into contact down to the mid-axils of the leaf-pair below, as e.g. in Hypericum calycinum and Epilobium parviflorum (see Fig. 2I). If the insertion width is less than a half but more than a quarter of the circumference, there will obviously be, not two, but four such contour lines traceable in each internode (one extending down from either margin of each leaf-base), which 
will terminate in the axils of the leaf-pair below, on either side of each mid-point, as in Vinca rosea. In cases where the insertion width is just equal to one quarter of the circumference, the four contour lines descending from any leaf-pair will ' pick up' (become continuous with) those arising at the node below. Hence the contour lines in this case will seem to continue uninterruptedly from internode to internode. If more than two leaves are present at each node, as occurs not infrequently on individual branches of plants normally having but two, the surface pattern exhibits a corresponding modification, as can also be well seen in the younger internodes in Hippuris vulgaris. ${ }^{1}$

Where the leaf arrangement is spiral the number of contour lines in each internode and the number of internodes through which they run is similarly determined by the leaf-divergence and the relative leaf-insertion width. We may take as an illustration the most frequently occurring arrangement, viz. the $\frac{2}{5}$ divergence. If with this divergence the insertion width approximates to $\frac{2}{5}$ of the circumference, three contour lines will be found in each internode, for every descending line will either ' pick up' a line descending from the neighbouring leaf next below, or will 'be picked up' by one descending from the next leaf above, as shown in Fig. II. With this configuration it follows that of the two contour lines arising from each leaf-insertion, one on each side, the one will terminate in the mid-axil of a lower leaf after running through two internodes, the other not until it has traversed three. If the individual is one with a right to left orientation (as shown in Fig. II), then the right edge line will be the long one and the left the short. Conversely, in the reverse orientation the line from the left edge will be long and will ' pick up.', that from the right edge will be short and will 'be picked up' by its neighbour. With the same leaf-divergence, but with an insertion occupying less than $\frac{2}{5}$ but more than $\frac{1}{5}$ of the circumference, there will be no actual 'pick-up', and hence five distinct contours will be traceable in each internode. For instead of a fusion line terminating in mid-axil, we shall now have two separate lines ending in each axil on either side of the mid-point, as occurs in Calystegia (see Fig. I9). If, still with the same divergence, the insertion is precisely $\frac{1}{5}$ of the circumference, these five lines will appear continuous from internode to internode, as described in a previous case.

But the biological pattern thus traced is not generally a strict rectilinear design. There is often some degree of convergence or curvature in

1 It must be understood throughout this account that where biological relations are expressed in fractions, these fractions represent an approximation and not mathematical exactitude. No doubt a certain amount of 'give and take' occurs between any leaf and its neighbours. This is of no consequence from the point of view of the general principles here under consideration. All that matters is that this biological 'give and take' is adjusted so that the final result (i. e. the sum of the fractions estimated in relation not to an abstract vertical axis but to the axis of biological symmetry) is an integer. For if it be acknowledged that the leaves are decurrent, then the course of the cell files and not precise measurement will be our means of determination. 
Anatomico-physiological Relations in the Spermophyte Shoot. I4 I
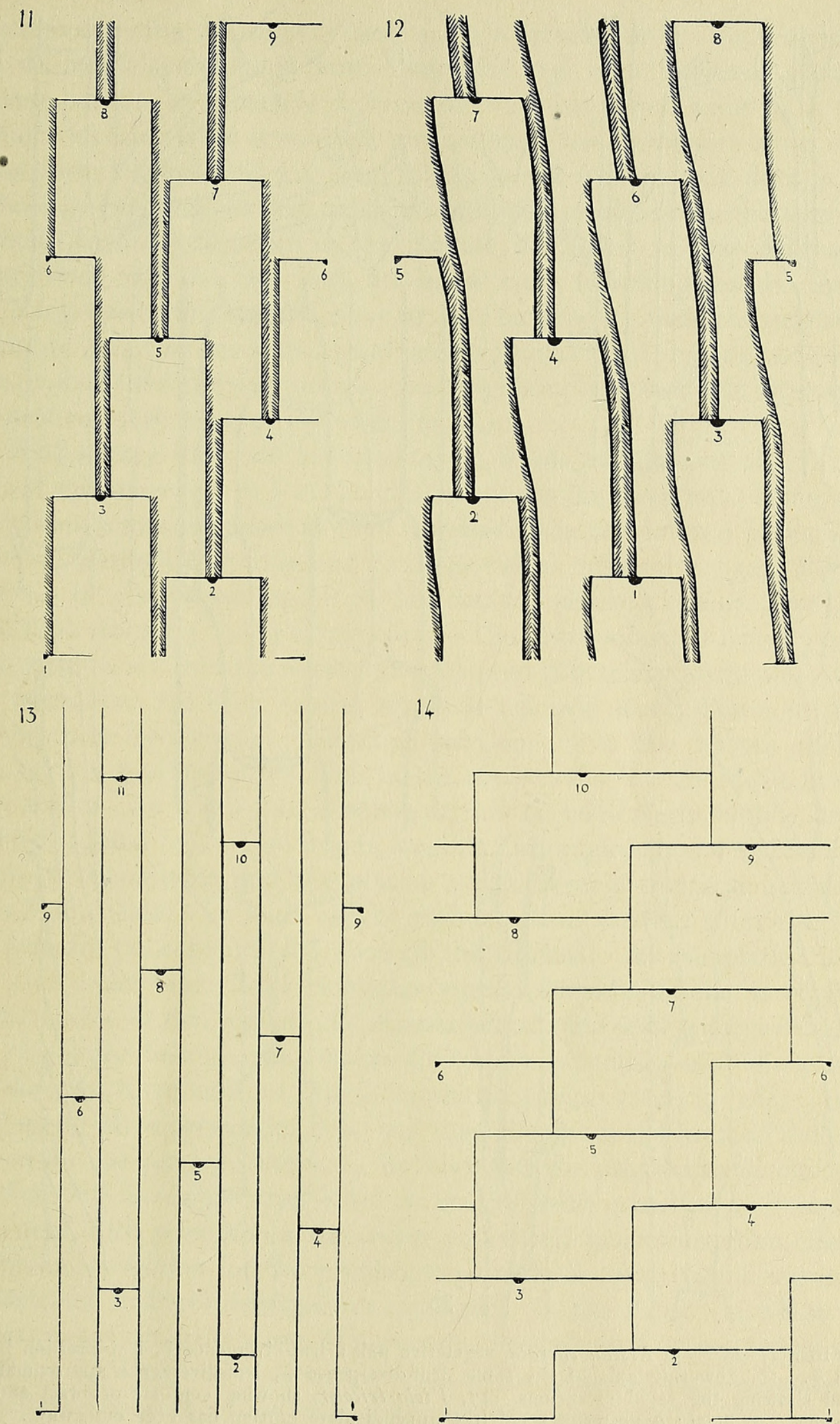

FIGS. I I-I4. Diagrammatic schemes to represent phyllotaxis; the axis viewed as if split longitudinally and spread out flat. I I, Veronica hederaefolia, leaf-divergence $\frac{2}{5}$, leaf-insertion approximately $\frac{2}{5}$. I 2 , Lopezia coronata, leaf-divergence $\frac{2}{5}$, leaf-insertion approximately $\frac{1}{5}$; the pattern shows a lateral skew. I 3 , Reseda odorata, flowering axis ; bract-divergence $\frac{3}{8}$, bract-insertion approximately $\frac{1}{8}$. I 4 , Viola tricolor, leaf-divergence $\frac{2}{5}$, leaf-insertion approximately $\frac{3}{5}$. 
I42 Saunders.-The Leaf-skin Theory of the Stem:
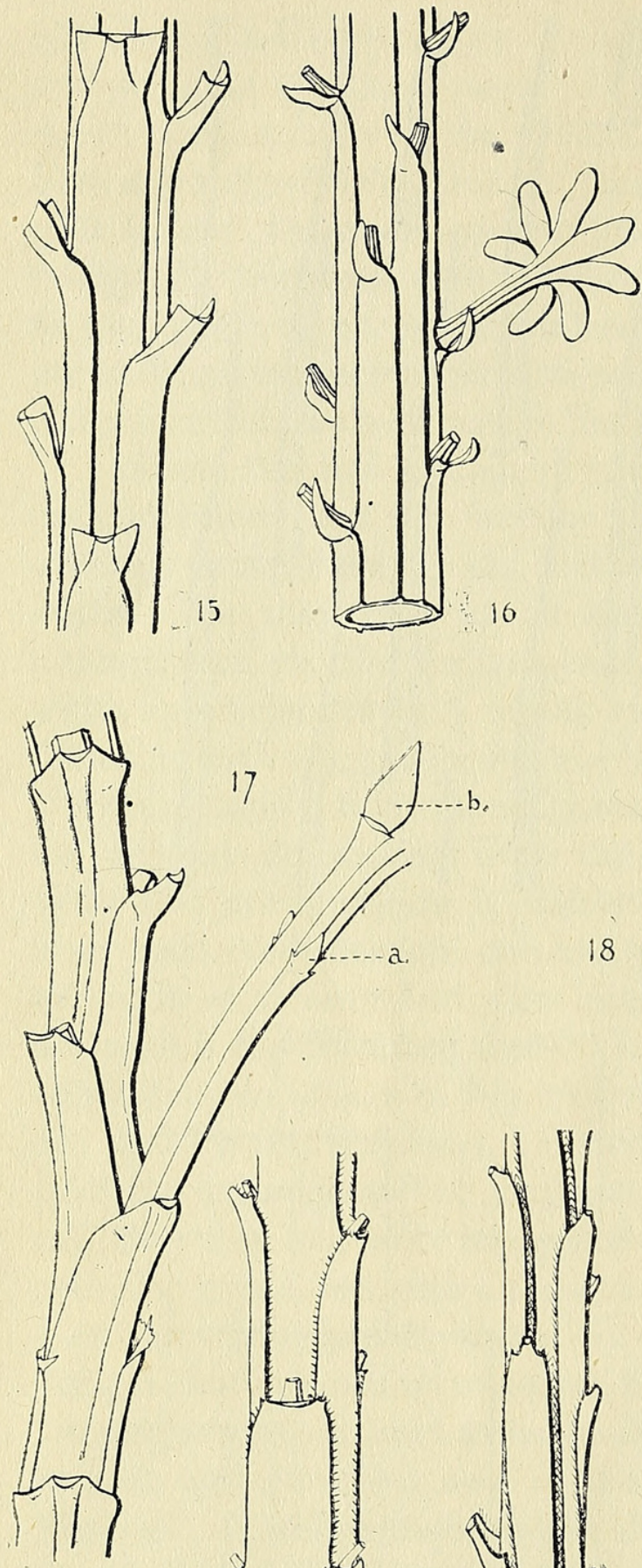

18
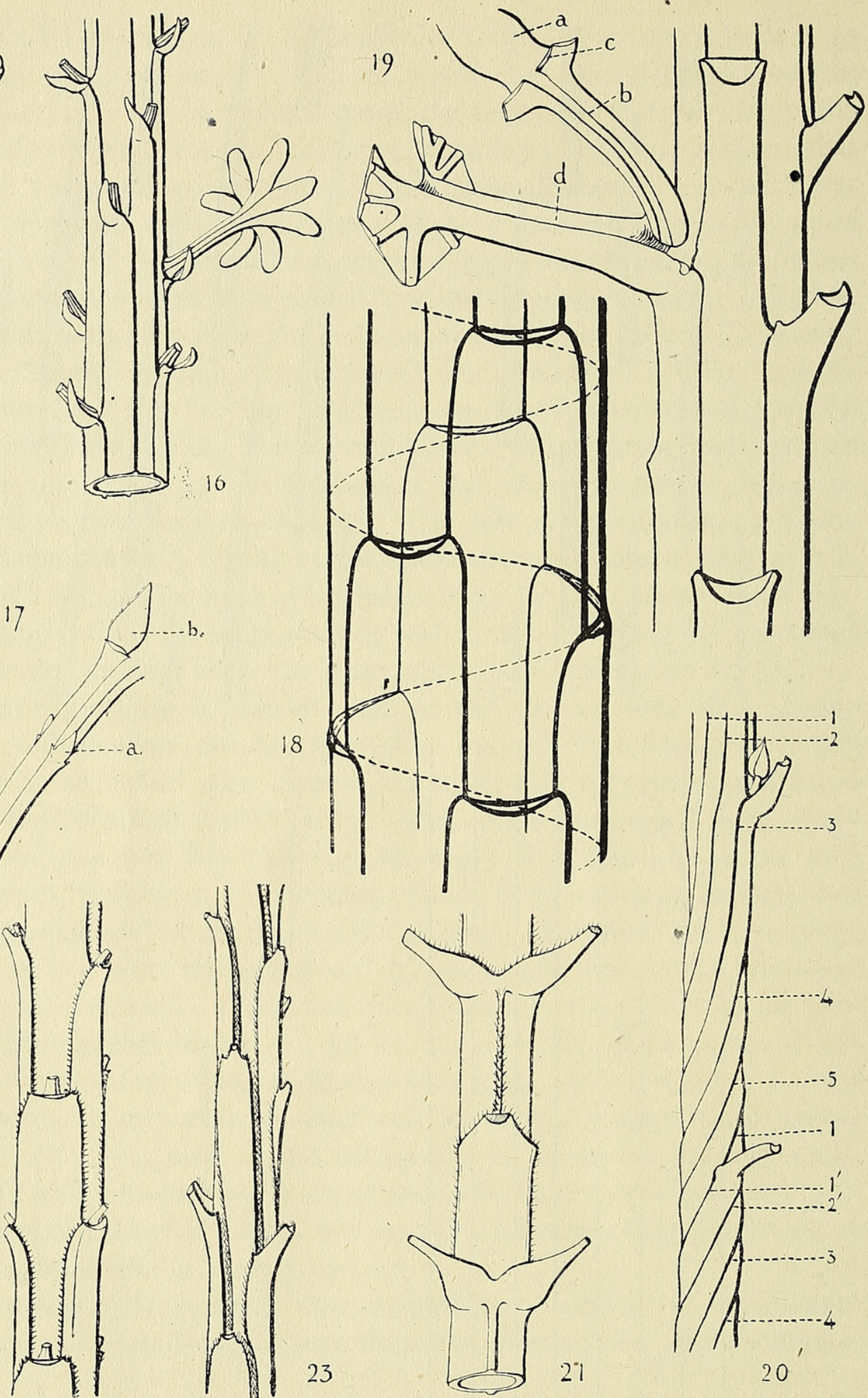

FIGS. I5-23. I5, Reseda odorata, vegetative axis; leaf-divergence $\frac{2}{5}$, leaf-insertion between $\frac{1}{5}$ and $\frac{2}{5}$. 16 , flowering axis of the same, leaf-divergence $\frac{3}{8}$, leaf-divergence approximately $\frac{1}{8}$; pedicel showing the sepal extensions. I 7 , Viola tricolor, showing contours of bract and sepal extensions. $a$. bract; $b$, posterior sepal (the appendiculate portion has been cut away). I8-20, Calystegia dahurica. I8 (diagrammatic), stem viewed as if transparent, phyllotaxis as in Reseda (Fig. I5); I9, $a$, unopened flower-bud; $b$, contour lines from the bracts which have been cut away at $c ; d$, channelled petiole; 20, after torsion. 2i, Epilobium parviflorum; cotyledons glabrous, hypocotyl ridge without hairs, leaf-petioles ciliate, internodes with ridge line surmounted with hairs. 22-23. Lopezia coronata, showing the leaf-extension edges flanked with a line of hairs. 22 , lower region of the stem, leaves opposite; 23 , upper region, leaves spiral. 
the outlines, or the whole may have a slight lateral skew. Such departure from an exact geometrical form may give rise to a deviation from the ordinary pattern, as is seen in Lopezia coronata (see Figs. I 2 and 23). Here, although we have (as it seems) a $\frac{2}{5}$ divergence in the upper part of the shoot, and an insertion width of $\frac{1}{5}$ giving the expected five contour lines in each internode, these lines do not continue uninterruptedly down the stem, but terminate in the axil, some in the median line, some to one side of the axillary bud. Of the two lines arising at each insertion the shorter one, after being ' picked up' at the start by one descending from the neighbouring higher leaf, continues through three internodes; the longer one descends through five, 'picking up' one from a neighbouring lower leaf after it has traversed two (see later, p. 153 and Fig. I 2).

With a very wide leaf-insertion, as in Viola tricolor and allied forms, where it approximates to $\frac{3}{5}$ of the circumference, the divergence being again $\frac{2}{5}$, only two contours appear in each internode, the two formed by each leaf extending through only one and two internodes respectively (see Figs. I 3 and 17). In the flower spike of Mignonette (Reseda odorata) we have a transition from a $\frac{2}{5}$ to a $\frac{3}{8}$ divergence. The bract-insertion being $\frac{1}{8}$ of the circumference, we find the same uninterrupted continuity of the lines (here eight in number, see Figs. 14 and 16 ) as in the case of a $\frac{1}{5}$ insertion with a $\frac{2}{5}$ divergence (see above). Contour relations of a like nature are also observed in the ultimate branches of the shoot axis, i.e. in the individual flower stalks. In Viola and Calystegia this is particularly clearly shown (see Figs. I7 and I9). Two bracts, large in Calystegia, quite small in Viola, accompany the flower, and are placed a considerable distance up the fullgrown flower stalk. In both plants contour lines starting from the bract insertions are traceable to the base of the pedicel. As the portion of the stalk above the bract level elongates; similar lines due to the outer sepals become visible in this region. In Reseda odorata the pedicels show longitudinal ridges and furrows, the number always corresponding with the number of sepals, which varies from four to as many as eight (see Fig. I6).

Among Monocotyledons it is less easy to obtain the kind of evidence required for our present purpose. In this class the production in the seedling of a well-developed hypocotyl or in the adult plant of an elongated leafy shoot with a length of internode and width of leaf-insertion offering favourable conditions for the exhibition of those features which are easily demonstrated in Dicotyledons is exceptional. In the shoot axis of certain families (e. g. Commelinaceae, Gramineae, Dioscoreae), however, these conditions are fulfilled, and here we are able to see that the surface configuration depends upon the same relations as in Dicotyledons.

In the Coniferae, on the other hand, there is abundant evidence that these relations hold, as, indeed, we might expect in view of the essential similarity of arrangement and development in this group and in Dicotyle- 
dons. In many Conifers, in fact, the leaf is so obviously decurrent that it is invariably described as such.

Enough has now been said to show the general nature of the evidence upon which the view here advanced is based. It has been made clear that as regards certain definite surface patterns which are visible on the shoot axis, the form of the quasi-geometrical areas which go to their make-up is the outcome of the particular leaf-divergence and leaf-insertion width. Also that the 'direction of fit' of these areas corresponds with the orientation of the leaf-spiral - that it is, in fact, merely another outward expression of the same internal relation. - These facts are patent to the eye, and their significance can scarcely be disputed. They lead directly to the conclusion that in Spermophytes the shoot axis consists throughout of an axial core enveloped in a covering of tissue of foliar origin-the leaf-skin. I have used the word 'skin' with intent, for the reason that it does not connote any precise number of cell layers. For although the evidence adduced relates only to the first hypodermal layer in addition to the epidermis, it may be premature at this point to assume that in no case does any deeper layer give indication of these boundaries.

By the downward extension of its tissue the leaf is braced against the stem, and in this way we may suppose obtains a better point dappui, an arrangement which may have its value where the petiole has to carry a large outspread lamina. As is well known, the subcylindrical petiole of many Dicotyledons is frequently channelled on the upper side. Where this character is well marked, there may be a distinct appearance of a wrap-over of the edges, as in Lopezia coronata, where hairs border either rim of the channel, thus continuing in this middle region the demarcation by hairs of the actual (here arched-over) edges which has been shown to exist for the potential edges of the downward extensions, and which in the expanded lamina takes the form of a fine ciliation.

The differentiation of the vascular tissue of the leaf in the higher plants begins, as we know, in the periblem, about at the level at which the leaf is conceived as arising from the axis, and develops in both directions, upwards, keeping pace with the increasing length of the free portion, and downwards, usually for a definite distance which varies with the particular type, until it makes connexion with an older leaf-trace at a lower level. Now, although there are good grounds for maintaining that the region of transition from the arrangement typical of one member to that characteristic of another is not necessarily identical for all the tissues involved, nevertheless, the very fact that the leaf-trace pursues a downward as well as an upward course of development renders it at least not inconceivable that the more superficial tissues may do so too.

A decurrent mode of development of the Spermophyte leaf seems to have been envisaged by Sachs, if we may judge from the diagrammatic 
representation which appears in the 'Vorlesungen', Fig. 305, and is here reproduced, although no actual statement to this effect occurs in the text. The leaf-primordium is here depicted as arising from a single horizontal cell layer, which undergoes division and growth in such a

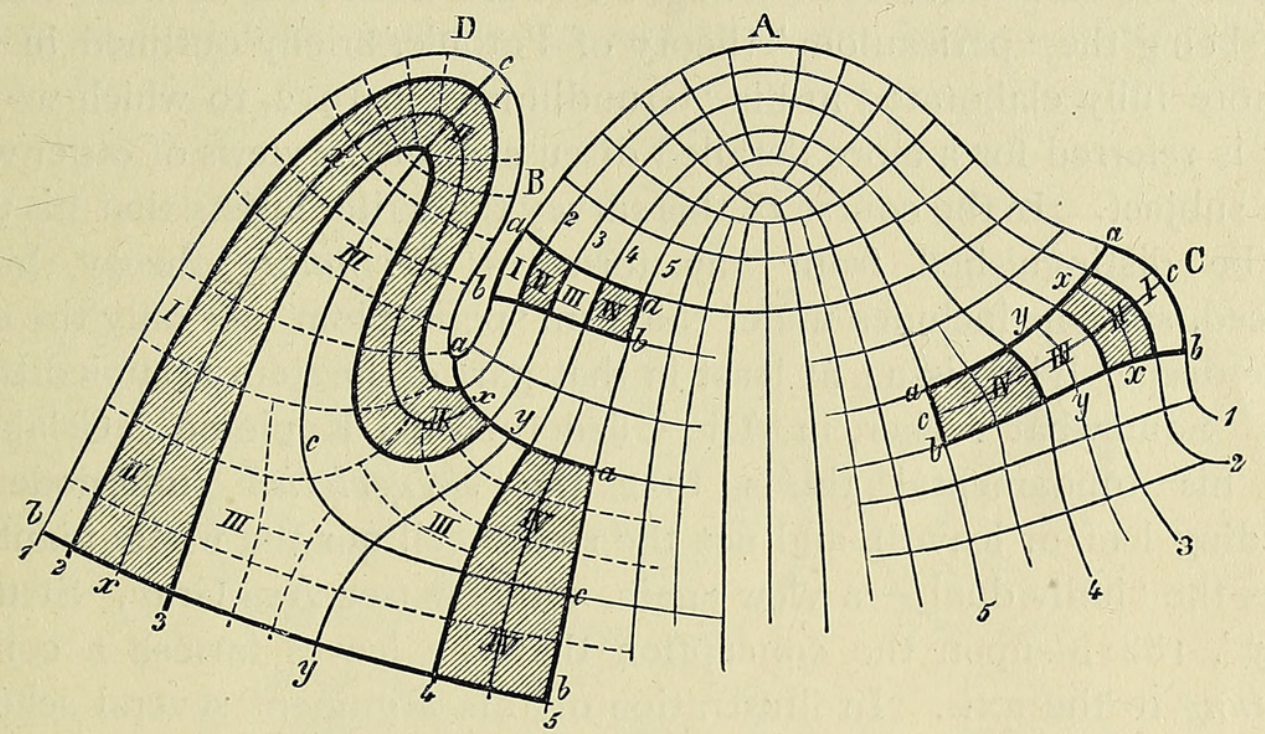

FIG. 24. Diagram to illustrate the mode in which leaves are developed from the growingpoint of a Phanerogam (reproduced from Sachs's 'Vorlesungen', Fig. 305, p. 569).

manner that the resulting tissue extends downwards for some distance below the axil, in a manner entirely in accord with the view put forward in the present account.

\section{Comparison of the Leaf-Skin Theory with the CONCEPTIONS OF OTHER WRITERS.}

That what in ordinary parlance we term the 'stem' is wholly or in part 'foliar' in nature is no new idea. It has existed in one form and another since a very early date in the history of Botany. In I84I-to go no farther back-Gaudichaud ${ }^{1}$ maintained that the unit of which a higher plant was built up consisted of (I) a downwardly developed system, the root (suppressed, as a rule, except in the embryo), and (2) an upwardly developed system distinguishable into $(a)$ a tigellar, $(b)$ a petiolar, and $(c)$ a laminar region, the two systems constituting a 'phyton', a series of 'phytons' making up the individual. Thus the stem as a plant member sui generis and distinct from a leaf was not recognized by Gaudichaud. By Hofmeister and Nägeli, on the other hand, the shoot was conceived as consisting of an axis on which were borne members of another orderthe leaves. This axis, according to Hofmeister, ${ }^{2}$ was not identical with the stem, but with its central region only. The outer tissue enveloping this core he held to be formed from the leaf-bases, through multiplication and

1 Mém. de l'Acad. des Sciences, Paris, I84 I.

2 Vergl. Untersuchungen, $185 \mathrm{I}$. 
extension of the component cells in the direction of their length. A somewhat similar view was held by Nägeli, who considered it probable that the tissue of the stem surface immediately surrounding the visible leaf-base belongs to the leaf. ${ }^{1}$ Various modifications of this conception of the dual nature of the stem have been brought forward from time to time, the most recent being the 'pericaulom' theory of Potonié, briefly outlined in 1902,2 and more fully elaborated in his 'Grundlinien' in 1912 , to which work the reader is referred for a more detailed discussion of the views of other writers on the subject. In the course of this survey the writer insists that his theory must be distinguished from any form of Berindung theory hitherto advanced, since he includes under the term 'pericaulom 'not only the cortex but the deeper-lying tissue, at least in that part of the stem occupied by leaftraces. Somewhat earlier, in 'Die Gliederung der Kaulome', ${ }^{3}$ Celakovský based his fundamental thesis that the Stengelglied (internode with succeeding leaf or leaves), and not the single cell nor the whole plant, constitutes the 'individual' - a view again not new (see Asa Gray, 'Structural Botany', 188I)-upon the conception that the leaves furnish a complete Berindung to the axis. In illustration of this argument several schematic drawings are given which, phylogenetic implications apart, the evidence here adduced fully supports (see Pl. IV, Figs. $7 a$ and I 9). For the moment, however, we are concerned less with the points of difference between the several theories than with the fact that they have this feature in common, that they rest for the most part on metaphysical conceptions, palaeontological argument and evolutionary theory. There is little or no direct evidence adduced which can be said to afford any very convincing proof of the position which it is sought to establish. In the present attempt to elucidate further the morphological nature of the shoot in the higher plants, the aim has been, by setting forth certain demonstrable facts and making clear their relation to the general anatomical scheme, to furnish evidence tantamount to proof of the existence of a 'leaf-skin' in the different Spermophyte groups, and by establishing this conception on a firm basis of fact to settle a question which ever and anon gives rise to renewed discussion, and upon which there still exists some division of opinion.

In this conception of the foliar nature of (at least) the superficial layers of the whole shoot axis, of the formation of a skin by downward extensions of the leaf-rudiments which are fused along their contiguous margins and which keep pace in their growth with the stem core, we find at least a partial solution of our original problem (see p. I35). We learn that it is to the surface character of the cotyledons that we must look for a guide to the surface character of the hypocotyl, since these two regions are morphologically one as regards their outer tissue. If the cotyledons are wholly or for

1 Abstammungslehre, I884.

2 Ber. d. deut. bot. Gesell., xx, p. 502, 1902.

3 Bot. Zeit., I90I. 
the most part free from hairs, the hypocotyl will almost certainly be devoid of hairs. If the free margins, more especially along their lower extent, are ciliate, then it is likely (though not inevitable, for the hairs peter out in some cases) that a hair line will be formed down each side of the hypocotyl. If the cotyledons are markedly hairy on the margins or the surface or in both regions, then we may expect that the hypocotyl will be hairy

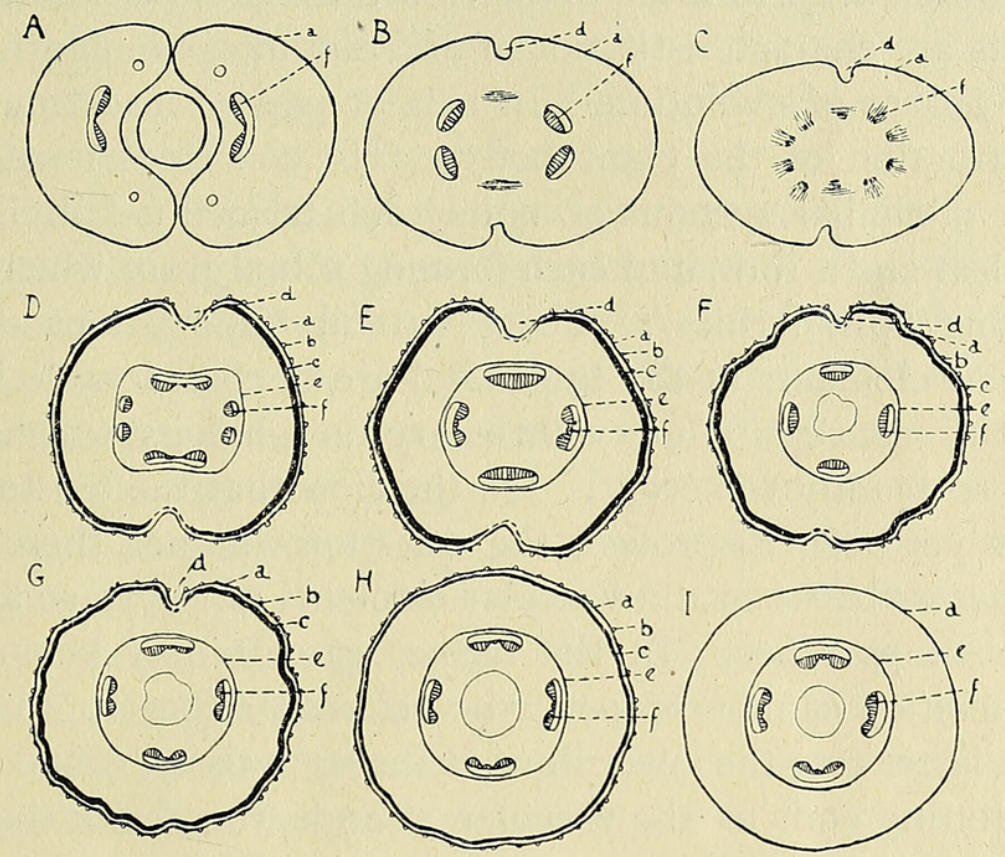

FIG. 25. A-I Ipomoea sanguinea, showing the appearance of the hypocotyl as seen in transverse section at successive levels from above downwards; $a$, epidermis; $b$, papillae, absent from the furrow; $c$, outermost layer of the cortex, containing anthocyanin; $d$, furrow ; $e$, endodermis ; $f$, fibro-vascular bundle.

all over. That is to say, where hair formation is a normal feature of the free basal margins of the cotyledons we may find the same character exhibited along their potential edges. This is as far as mere outward examination of the hypocotyl will carry us. The determination of the morphological nature of the axial core is a more difficult problem. In seedlings of the Ipomoea type we have a typical stem arrangement of the vascular tissue (xylem and phloem superposed) throughout the length of the hypocotyl (see Fig. 25). The opposite extreme condition in which a root arrangement (xylem and phloem alternate) is found extending up the hypocotyl to the cotyledon node has been recorded by various authors. This alternate disposition may even come about in the petioles before the cotyledon traces enter the hypocotyl as has been described by T. G. Hill'1 in Piper cornifolium. A similar condition has been found by Tansley and Thomas ${ }^{2}$ to exist in many members of the Rhoeadales and Ranales. In a detailed investigation of the vascular tissue in the seedlings

1 The New Phytologist, vol. iii, I904; also Ann. Bot., vol. xx, I906.

2 The New Phytologist, vol. iii, I904. 
of Dicotyledons especially, Chauveaud ${ }^{1}$ has shown that the transition from the alternate to the superposed arrangement may take place at any level in the hypocotyl. He further concludes from the appearances at successive levels that this transition results from the gradual disappearance, as we proceed up the hypocotyl, of the vascular elements of the root and their replacement on the alternate radii by the vascular elements of the cotyledon traces, from which observation he is led to the view that the superposed and alternate arrangements are characteristic, not of different morphological members, but of different phases of evolution. In a later paper ${ }^{2}$ he formulates his idea of the construction of the plant body. He conceives it as composed of a succession of similar systems or units, each termed a 'phyllorhize', consisting of a leaf and a root, and each forming a bud from which is developed the succeeding 'phyllorhize'. These careful observations on the course of the vascular elements in the hypocotyl are of considerable interest, quite apart from this conception of evolutionary morphology which one may not be disposed so readily to accept. On the view that the existence of a stem axis has not yet been disproved, the question whether there is continuity or merely contact between the vascular elements of the trace and the root is one of prime importance. In the former case it may be urged that the region of transition cannot properly be referred either to the stem or the root; in the latter case the lower limit of the stem tissue would be defined by the interdigitating ends of the vascular strands, the foliar character of the external tissue being unaffected on either view. This latter point being the one with which we are here mainly concerned, it may now be well to describe the topographical features of a few illustrative cases in further detail.

\section{Further Details of Surface Topography in some Illus-} trative Cases among Angiosperms and Gymnosperms.

\section{Dicotyledons.}

Hypericum calycinum. Leaves opposite. A longitudinal welt marking the line of junction of the confluent leaf extensions runs down either side of the internode, starting from the points where the leaf-blades meet and terminating in mid-axil at the next node below.

Epilobium parviflorum. Leaves opposite. Cotyledons glabrous. Hypocotyl glabrous, with a longitudinal welt on either side extending down from the points where the cotyledon blades coalesce. In the internodes of the young stem the raised contours representing the lines of fusion may be further marked by a distinct line of hairs (see Fig. 2I).

Ruellia amoena (Acanthaceae). Leaves opposite. Cotyledons with a short pile on the upper surface of the petioles, otherwise glabrous. Hypocotyl and stem with two well-marked lines of hairs extending through-

1 Ann. des Sci. Nat., Bot., t. xiii, 1911.

${ }^{2}$ Comptes rendus, t. clviii, p. 343, I9I4. 
out the internode from leaf junction above to mid-axil below, well developed even in the youngest internodes.

Asclepias linifolia. Leaves opposite. Internodes with two conspicuous lines of hairs or with one line broad and well defined and the other narrow or even wanting. In the last-mentioned case the positions of the one line in successive internodes lie on a continuous spiral, as in Stellaria media (see below), though occasionally the direction is observed to become reversed even in unbranched stems standing erect.

Stellaria media. Leaves opposite. Stem glabrous except for a single well-defined line of hairs extending from one of the two leaf junctions at each node to the mid-axil of the leaf immediately below. A crosssection of the middle region of the internode shows a ring of four vascular bundles symmetrically disposed. The two in line with the midribs of the leaf-pair above are small; the alternate pair occupy a more extended arc. It is exactly opposite one (or sometimes both) of these larger double bundles that the hairs arise (see Fig. IO). In each successive internode this line shifts through a quarter of the circumference, always in the same direction, so that it traces a spiral round the axis. The direction of the spiral may be either to the right or to the left, and may be in opposite directions in different branches on one individual. Among most of the plants examined the lowest internode on the chief axes was without this hair line ; sometimes this was the case also with the next one or more. Once having appeared, however, it continues almost without exception uninterruptedly up the stem. Now and again an internode may be found with a second hair line, sometimes weaker, sometimes as well marked as its fellow, starting. from the other (opposite) leaf-junction. Attempts to relate the occurrence of two lines of hairs with any other external morphological feature proved unsuccessful. So far as appeared, the demarcation of the second leaf-extension fusion line in any internode was not directly related to the degree of vigour of development, symmetrical or otherwise, of the axillary buds either at the node above or below. In other words, no expectation could be formed as to when two lines would be found. There is, however, some indication that a second hair line is more frequent in plants grown in dry soil and fully exposed to the light-a conclusion quite in accord with that arrived at in other cases. Certain other relations of the single, or of the more pronounced line if two are present, appear to be more strictly laid down. When this hair line appears on the lowest internode of a vegetative lateral axis it always occurs on the adaxial side, but the direction which the spiral will then proceed to take can only be ascertained by inspection of the next (second) internode. In the flowering region, where the axillary bud of both leaves usually develops, the main axis (the central flower stalk of each cyme) becomes pushed at each successive node to one side (a displacement which does not occur when both 
axillary buds develop in the vegetative region) and curves outwards and downwards on the side of the stem opposite that on which the hair line is formed in the internode immediately below. A well-marked line of hairs extends along the whole length of this flower axis on the inner (convex) side, i. e. the side which faces the geometrical centre of the whole system, and arises from the insertion of the posterior sepal whose edges lie outside its neighbours, and whose insertion width is so narrow that the two lines which we might expect to find apparently come into contact and form the single track which we see. On both the axillary axes which spring from the same node the hair line develops on the adaxial side, as has been described for the case of the lateral branches in the vegetative region. These relations have been observed also by Lundström, ${ }^{1}$ who accounts for the suppression of the second line of hairs in the internode beneath the flowering node on the supposition that it would be useless in this position and hence is not formed. But this argument does not meet the case in the vegetative region. It would rather seem that hair formation is the outcome of a certain physiological condition which is not usually attained in the basal internodes, but is reached and maintained at higher levels, and may even now and again exceed this normal limit and so lead to the formation of a second hair line. The direction of shift of the single line is not apparently predetermined, but is the result of a combination of causes affecting equilibrium at a particular moment.

Upon comparing individuals growing in different situations, it becomes evident at once that the general uniformity of hair distribution characteristic of the axial surfaces is not manifested in the free region of the sepals, which varies greatly in degree of hairiness. In some plants the whole of the surface exposed in the unopened bud is hairy ; in other individuals it may be difficult to find a single hair. But even though there be but one on the posterior sepal itself, the hair line marking the boundaries of its extension down the pedicel is as conspicuous as in those cases where the unopened bud is hairy all over. The production of hairs on the free surface of the sepal takes place in response to the particular conditions prevailing during the development of the axis, and has no hereditary significance. The hair line marking the boundaries of the sepal extensions is an inherited feature related to a definite morphological configuration, and makes its appearance as soon as the internode has an appreciable length.

The general occurrence in Stellaria media of the single well-marked hair line in the internodes suggests (I) that an inequality of growth analogous to, if not identical with that which leads to the transition from an opposite to a spiral leaf-arrangement in so many.species, or which finds expression in the circumnutation of the shoot tip, is inherent or invariably becomes set up in this species ; (2) that this inequality is reflected along the lines of junction 
of the leaf-extensions, although it does not cause any obvious displacement of the leaves themselves; and (3) that exceptionally it may be sufficiently lessened temporarily as to do away with any outward effect of asymmetry and hence the two equal hair lines. This interpretation of the Stellaria configuration appears to be more consonant with the facts than the explanation offered by Eichler, ${ }^{1}$ who considers that although the leaves are opposite and decussate, yet, since one member of the pair begins to develop a little earlier than its fellow, we should regard them as in fact spirally arranged with a leaf-divergence of $\frac{1}{4}$. To which conception we must presumably add the idea of a one-sided effect on the leaf-extension in order to account for the general absence of the hair line from one edge of the leaf-insertion. A similar one-sided disposition of the hair line is sometimes to be observed in seedlings. In some individuals of Cosmos bipinnatus, for example, a distinct line of hairs was present on one side of the hypocotyl, but except for two or three immediately beneath the point where the free margins of the cotyledons coalesced, the opposite side was destitute of hairs. Yet it surely would be somewhat fanciful on this ground to apply the conception of a $\frac{1}{4}$ divergence to the cotyledons. In other species showing a difference between the two sides of the axis, the normal condition may be one in which this inequality is much less pronounced, as in the case where two hair lines commonly occur but the one is much weaker than the other (observed in seedling plants of Bidens ferulaefolia, D.C.). It has seemed necessary to dwell at some length on the case of Stellaria, since a mere statement of the facts without further analysis would make it appear that this configuration was not amenable to interpretation on the theory of the leaf-extension as here set fort $h$.

Certain hairy-leaved species of Veronica. In $V$. hederaefolia, $V$.arvensis, and $V$. polita, as well as in the familiar case of $V$. Chamaedrys, a definite hair pattern is exhibited when the plants are growing under certain conditions. That this fact has hitherto only been generally recognized for $V$. Chamaedrys is due no doubt to the circumstance that in this species the hairs are of one kind, and that the rest of the surface is nearly or quite glabrous; whereas in the other species named the hairs are usually of two kinds, the one long, needle-like, and spreading, the other short and closely set, forming a sort of pile. Along the line of fusion of the leaf-extensions we find a tract covered with pile, but with few if any of the long hairs which are abundant over the rest of the surface. This appearance is particularly clear in $V$.hederaefolia. In this species the cotyledons and hypocotyl are frequently glabrous. Under suitable conditions, however, hairs develop on the margins of the petioles and extend down opposite sides of the hypocotyl in two vertical lines, petering out, it may be, before reaching the root, the rest of the surface being desti-

1 Bliithendiagramme, II, p. I7. 
tute of hairs. Under conditions still more favourable to hair formation, on the other hand, the whole surface may be covered with hairs. It becomes evident, in fact, that the lines of fusion of the cotyledon extensions remain invisible, or are brought out, or obliterated, according to the extent to which the conditions happen to be favourable to hair development. In the four species of Veronica named above, the first leaves are always opposite. This arrangement may persist up the stem $(V$. arvensis, $V$. Chamaedrys), but in the flower spikes, if not before, the arrangement becomes spiral with a $\frac{2}{5}$ divergence. In $V$. hederaefolia and $V$. polita, where the flowers are solitary and axillary, the spiral arrangemént is assumed at an earlier stage. Coincident with this change in the leafarrangement we find in individuals in which the hair lines are apparent a corresponding change of pattern. In place of two lines to the internode, both extending only from one node to the next, we now have a three-line pattern resulting from a 'pick-up' along the lines of fusion of the kind already described (see p. 140 and Fig. II). Of the two lines arising at each insertion one now descends through two internodes and the other through three, the one from the right or from the left edge being the longer of the two according to whether the individual is one in which the spiral proceeds from right to left or from left to right. In $V$. hederaefolia a welldefined hair line is also traceable along the whole length of the flower stalk, marking the line of fusion of the extensions of the two postero-lateral sepals, and ending in the mid-axil of the subtending leaf where it meets the hair line on the main axis terminating at the same point.

Lopezia coronata. Leaves opposite below, becoming spiral above, upper surface slightly hairy towards the base, margins finely ciliate. Here again under the appropriate conditions two lines of hairs are developed on the hypocotyl, descending from the points where the free margins of the cotyledons coalesce (see Fig. 4). A decussate arrangement of the leaves is continued for perhaps fourteen or fifteen nodes, a difference in the level of insertion of the two members of a pair, which is slight to begin with, becoming very considerable higher up. The internodes in this lower region show two contour lines flanked by lines of hairs which are absent from the surface elsewhere (see Fig. 22). Some interest attaches to a case in which an irregularity in the leaf arrangement occurred in view of the conception of the 'potential' edge which has been given above (p. I38). In the specimen in question two leaves were borne at the first and second nodes, a slight difference in the level of insertion being noticeable in the latter case ; at the third node only one leaf was formed, while three appeared at the node above. It was evident that one of the pair belonging properly to node 3 had become fused with the axis in its upward development, and hence only became free at the node above its true insertion. In consequence of this disarrangement, the leaf which was carried from node 3 and one 
of those properly belonging to node 4 were placed so near together that a deeper fusion of tissue than usually takes place may be supposed to have existed, with the result that the line of contact between them no longer possessed the character of a 'potential' edge and hence produced neither hairs nor contour ridge. In the upper region of the stem, as already described (p. I43), the leaf-divergence is $\frac{2}{5}$ and the leaf-insertion width perhaps a trifle more than $\frac{1}{5}$ of the circumference. The contour lines diverge
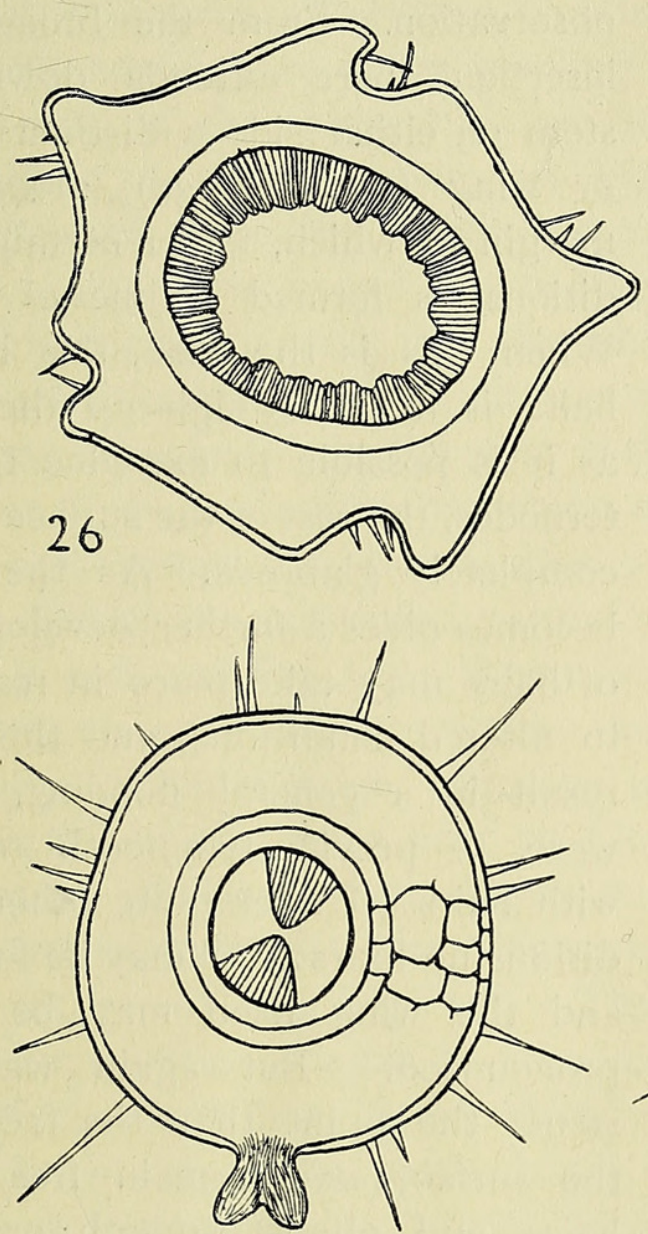

28

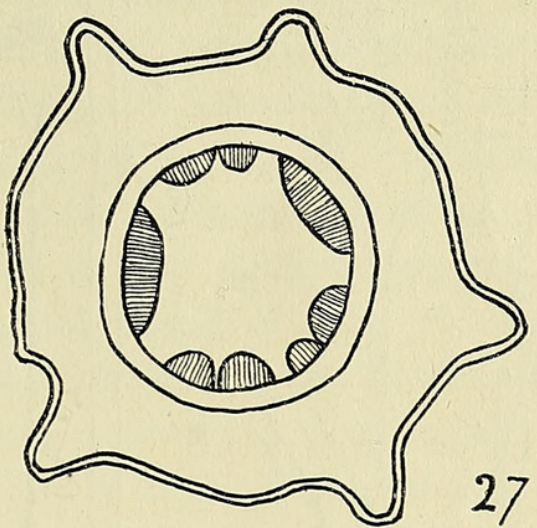

27

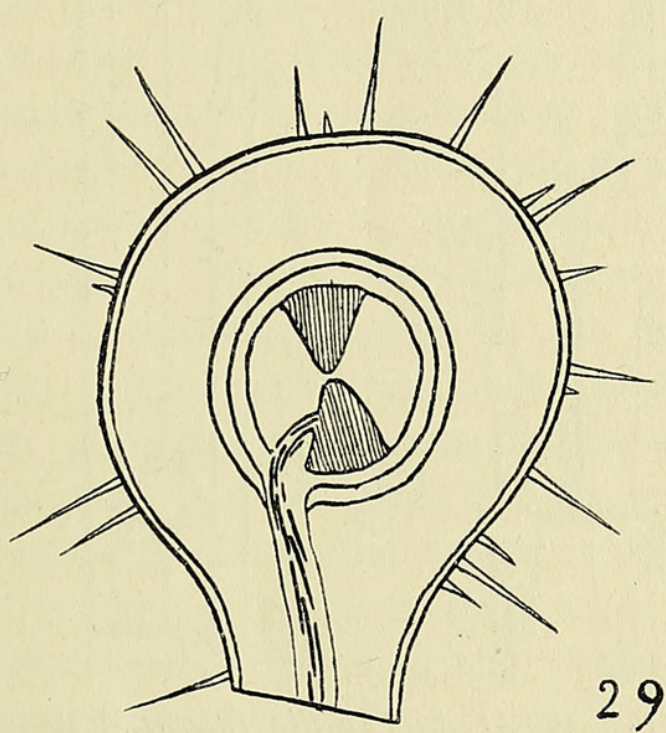

FIgs. 26-29. 26, Lopezia coronata, stem in transverse section showing the contour lines of the leaf-extensions as eight ridges flanked with a line of hairs. 27, Calystegia dahurica, showing similar ridges without hairs. 28-29, Antirrhinum Orontium, hypocotyl in transverse section showing an early and a later stage in the development of an exogenous adventitious bud.

slightly from a straight course, so that of the two terminating at each node one ends in mid-axil, the other to the side and close to one of the minute stipules. The 'lie' of the pattern is therefore not truly in line with the axis, but slightly askew. Owing to this cause and to some slight departure from a parallel course, the two contour lines from each leaf-insertion now run through three and five internodes respectively (see Figs. I2 and 23) instead of only through two and three internodes, as is the case with the same arrangement when the fusion lines run parallel to the axis (as shown in Fig. II). As the hair lines flank each ridge and as contiguous hair lines 
become merged we get a pattern of eight ridges and five hair lines to the internode (see Figs. 12 and 26).

Lobelia fulgens. Leaf-divergence $\frac{2}{5}$, leaf-insertion width about $\frac{2}{5}$ of the circumference. The contour relations here are the same as those described for Veronica, but the stoutness of the Lobelia stem and its deep red colour, against which the colourless hairs are particularly conspicuous, ${ }^{1}$ render
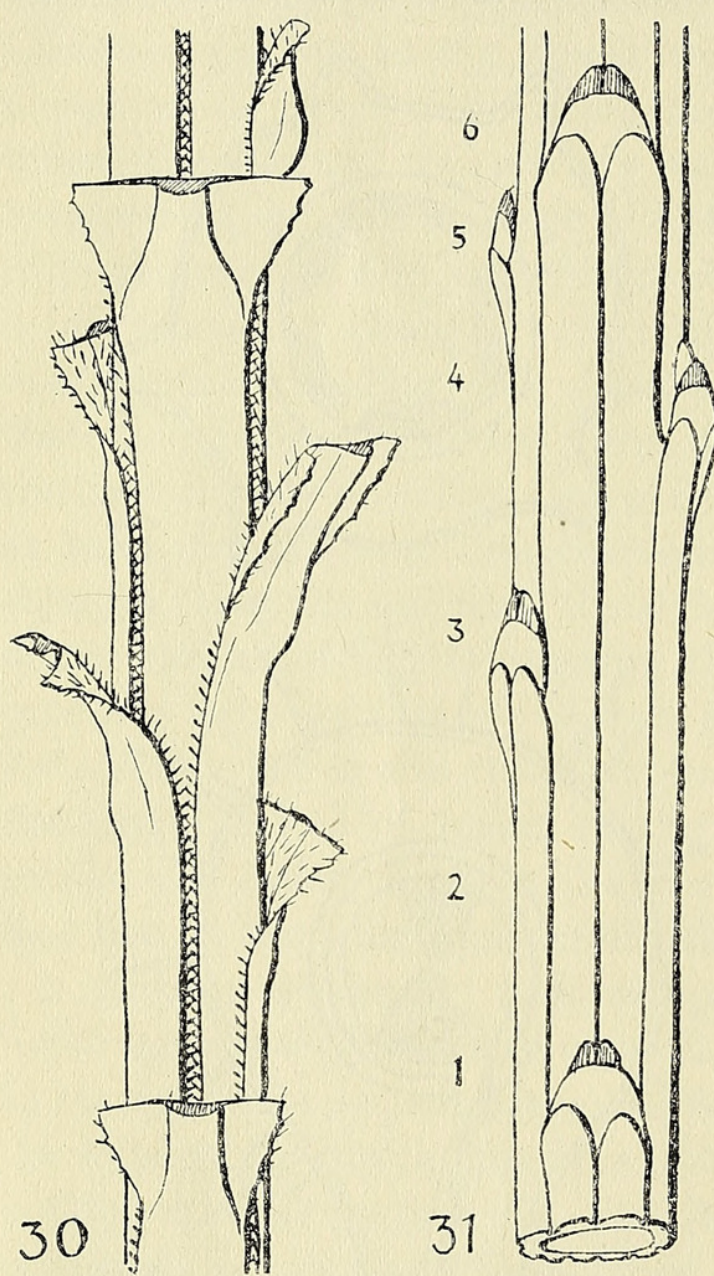

Figs. 30-3i. 30, Lobelia fulgens, leafdivergence $\frac{2}{5}$; leaf-insertion approximately $\frac{2}{5}$, with decurrent wing margined by hairs. $3 \mathrm{I}$, Cytisus purgans, leaf-divergence $\frac{2}{5}$, leaf-insertion approximately $\frac{1}{5}$; the number of contour lines is doubled owing to the additional one formed in line with the midrib (nodes numbered from below upwards). it specially favourable material for observation. From the broad leafinsertion there extends down the stem on either side a distinct flange or wing (see Fig. 30), along the margin of which, under certain conditions, is formed a line of hairs. When this is the case, this line of hairs is found as high up the stem as it is possible to examine the internodes, the rest of the surface being completely glabrous. As the stem becomes older a further development of hairs may take place in response to altered conditions, and this may result in a general flooding, as it were, of previously smooth regions with hairs. Under quite other conditions no hairs at all may be formed, and the wing itself may be little pronounced. But again we may stress the point that the fact that the surface may remain free from hairs and almost smooth or may show a blurring of the original pattern is beside the mark. Our aim is to prove that certain boundaries exist, and that under suitable conditions they become clearly defined.

Convolvulus arvensis, Ipomoea cocinea, Ipomoea sanguinea, Calystegia dahurica (Convolvulaceae). In this family contour ridge lines are a very characteristic and conspicuous feature, and are traceable despite any degree of torsion in all regions of the stem (see Figs. I9 and 20). In Calystegia

1 As the anthocyanin in this species occurs in the epidermal layer this distribution is remarkable. We have here, as we shall have occasion to note again later elsewhere, a sharp delimitation within tissue accompanying different development. At an early stage all the epidermis is coloured, but as hairs and guard-cells become differentiated, the colouring matter disappears from these specialized cells. 


\section{Anatomico-physiological Relations in the Spermophyte Shoot. I 55}

dahurica, which we may take as an example, the leaf-divergence is $\frac{2}{5}$ and the insertion width between $\frac{1}{5}$ and $\frac{2}{5}$, hence, as explained above (p. I40) and as shown in Figs. 18 and I9, no actual 'pick-up' occurs. Each contour ridge runs a separate course through two or three internodes according as it starts from one side or other of the insertion, and the two adjacent lines from neighbouring leaves (one from the right edge and one from the left) terminate in each axil. We thus get five contour lines in each internode. The stem is coloured with anthocyanin, and this is ordinarily confined, as in the seedling, to the layer beneath the epidermis, where most of the chlorophyll is also located, A cross-section through the middle of the internode (see Fig. 27) shows a ring of five vascular bundles, each extending through a considerable arc midway between two ridges. The second and succeeding layers of the cortex become converted into collenchyma, and the whole central tissue of each ridge may be thus thickened, but the outermost layer containing the anthocyanin remains unchanged. At the crest of the ridge, however, i. e. along the line of fusion of the leaf-extensions, there is frequently a gap of one or two cells in the anthocyanin ring, just as there occurred a similar break in the furrow (fusion line of the cotyledon extensions) of the hypocotyl in Ipomooa (see above, p. I 38 , and Fig. 25). When this is the case these colourless junction cells may undergo collenchymatous thickening as well as those lying deeper. The same 'potential edge' character is thus common to the furrow of the hypocotyl and the ridge lines on the stem. The axillary flower stalk is marked by similar contour ridges, due in the lower region to the downward extensions of the two bracts and in the upper portion to those of the outer sepals (see Fig. 19). The petioles are stout and channelled, and their insertion, owing to their angular outline, gives rise to special trace lines which form a subsidiary pattern within the larger configuration. Such subsidiary patterns are not infrequently present when the petiole is four-angled, as is seen in Rivina humilis, especially if the leaf is large and compound, as e. g. in Phaseolus multiflorus.

Viola tricolor. Leaf-divergence $\frac{2}{5}$, leaf-insertion width about $\frac{3}{5}$. The stem shows two well-marked contour ridges in each internode. Of the two arising from each insertion one descends through only one internode, the other through two (see above, p. I43, and Figs. I4 and 17). As is the case in Calystegia, the flower stalk exhibits ridge lines due to the two bracts, minute as they are, which are placed some distance up the pedicel. As the region above the bract level elongates, similar lines arising from the posterior sepal can be traced passing between the bracts (which are not near enough together to furnish a ' pick-up') along the whole length of the flower stalk.

Reseda odorata. Leaf-divergence in the vegetative axis $\frac{2}{5}$, leaf-insertion width between $\frac{1}{5}$ and $\frac{2}{5}$. General scheme similar to that of Calystegia (see 
above, p. I40, and Fig. I5). In the flower spike the arrangement changes to a $\frac{3}{8}$ divergence with a bract-insertion width of $\frac{1}{8}$, the eight contour lines thus produced being continued uninterruptedly along the axis (see Figs. I 3 and I6). On the individual flower stalks from five to eight lines demarcating the downward extensions of a corresponding number of sepals are plainly visible.

Cytisus purgans. Leaf-divergence $\frac{2}{5}$, leaf-insertion width about $\frac{1}{5}$. With this combination we should ordinarily expect a continuous five-line configuration, but here we find ten lines (see Fig. 3I). This doubling of the

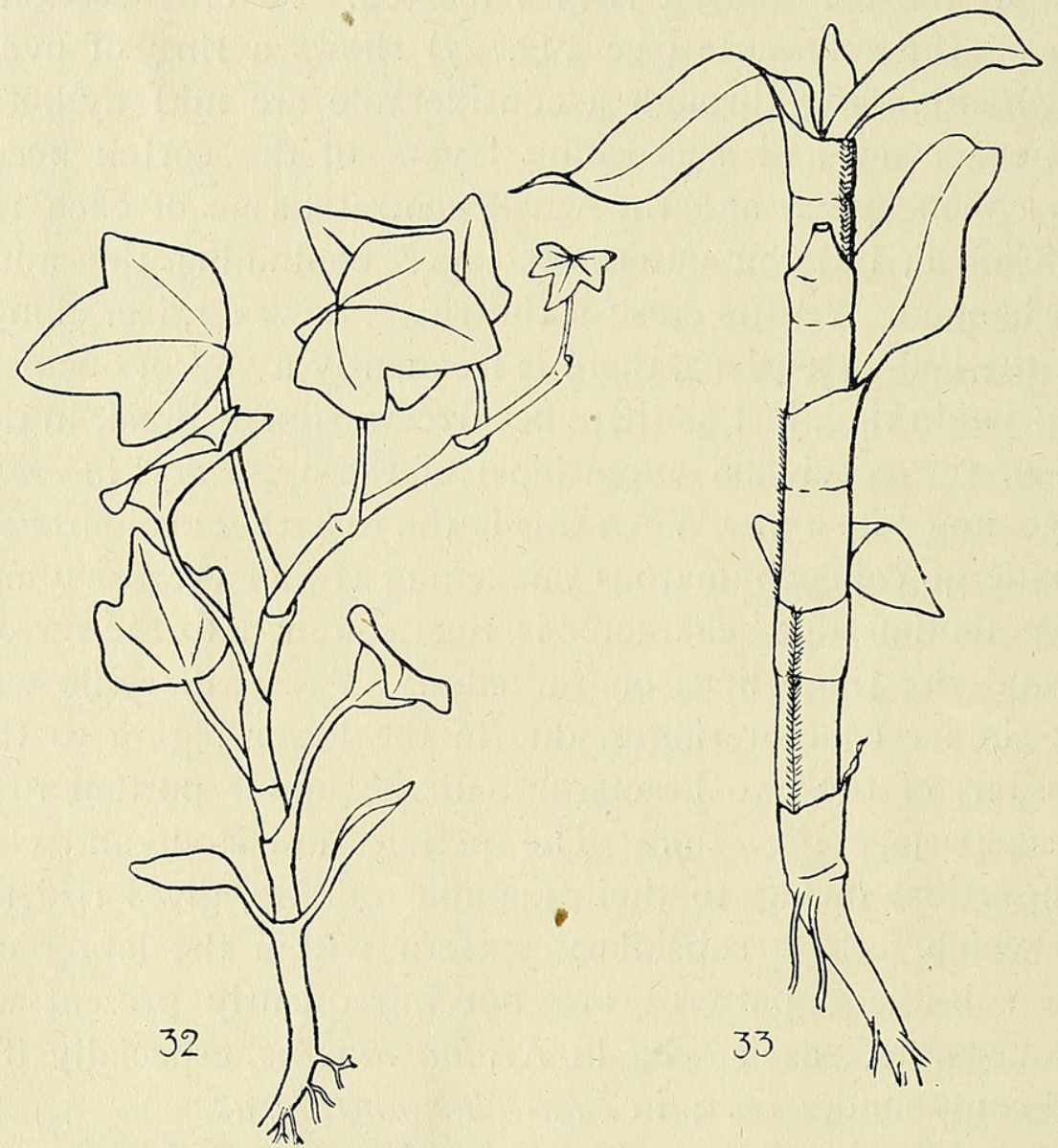

FIGs. 32-33. 32, Hedera Helix, seedling plant; a dicotyledon type with circular leaf-insertion. 33, Tinantia fugax, a monocotyledon type with a conspicuous line of hairs along the line of fusion of the edges of the tubular sheath and of the leaf-extension; cotyledon apex withered.

contours is due to the fact that in this species the free portion of the leaf is reduced to two small paired membranous flaps, and the five additional lines arise at their point of junction. The appearance that these membranous flaps would readily peel off, bringing away a longitudinal green strip beneath them, is suggestive of that actuality which in its more pronounced form, when the leaf is obviously decurrent, is universally recognized.

Hedera Helix. Leaves spiral. In the seedling it can be seen that the leaf has an insertion which completely embraces the axis, hence each internode is entirely covered with the downward extension of a single leaf (see 
Fig. 32). This example is of particular interest in view of the strict comparison it affords with the monocotyledonous condition as exemplified in the Gramineae, Palmae, Commelinaceae, and other families.

\section{Monocotyledons.}

Tinantia fugax, Commelina coelestis, Tradescantia fuminensis, Zebrina pendula (Commelinaceae). The first three plants furnish perhaps as striking an illustration as can be found of the demarcation of the fused edges of the leaf by a line of hairs. In each of the genera the leaf-insertion embraces the axis. Above the node level the leaf forms a short tubular sheath, surrounding but free from the axis, before it expands into the free lamina, the basal margins of which are ciliate. On the side of the sheath which represents the fused edges a well-marked line of hairs is present, which, except in Zebrina pendula, is continued past the node and down the whole length of the internode beneath, until it terminates to one side of the mid-point in the axil of the next leaf below (see Fig. 33). Elsewhere the surface is glabrous except at the insertion level in Zebrina where hairs occur especially over the spot $^{1}$ where the axillary bud or a root will break through later. In the flowering region, as is so often the case also in Dicotyledons, the plant may become generally hairy (Tmantia). In the first two genera named above ${ }^{2}$ there are no hairs on the well-developed hypocotyl, a fact which becomes comprehensible when it is seen that the margins of the cotyledon sheath, unlike those of the leaves, are without hairs.

Gramineae. In the adult plant it needs no very close examination to see that the base of the split leaf-sheath is not the lower limit of the external tissue of the leaf, and that the 'skin' or outer surface, now fused with the axis, is continued down for one internode below the level of insertion; while in regard to the morphological nature of the structures present in the seedling the view arrived at by Sargant and Arber, ${ }^{3}$ as the result of a detailed study of this family, is not only entirely compatible with the position here taken up but affords it a certain measure of support, notwithstanding the additional complications which render the elucidation of the Gramineae particularly difficult. For it may well be that such a process of fusion as is envisaged in the present account preceded phylogenetically the further fusion which these authors hold to have occurred through close juxtaposition of the cotyledon stalk with the hypocotyl and thus to have formed the 'mesocotyl'.

Dioscorea quinqueloba. The leaf arrangement and insertion, and the resulting surface pattern, are so similar to the configuration seen in the

1 Arising presumably as the direct outcome of pressure or strain set up by the underlying protuberance.

${ }^{2}$ Seedlings of the two other types were not obtainable.

${ }^{3}$ Ann. Bot., vol. xxix, 1915 . 
Convolvulaceae that the description which has been given for Calystegia may be taken as applying equally to the present case.

\section{G ymnosperms.}

Coniferae. The obviously decurrent character of the leaves in the adult shoot of many species has already been mentioned. In a seedling plant of Juniper, for example, it is evident at a glance that between successive whorls of three leaves the surface of the stem proper is nowhere exposed. The three longitudinal contact lines seen in each internode extend throughout its length, terminating in the mid-axils of the whorl below. In an Araucaria seedling a 'pick-up' pattern after the manner of a Dicotyledon is especially conspicuous, while in Pinus maritima (Fig. 8) and Picea orientalis, Carr, as mentioned above (p. I38), we have a hypocotyl with ridges and furrows corresponding in number with the cotyledons.

\section{Evidence From the Pteridophyta.}

A discussion of the question whether the leaf-skin theory is generally applicable to the Pteridophyta lies outside the scope of the present paper. It will not however be out of place to call attention to certain features in one or two types which suggest that the same relation may exist among Vascular Cryptogams as has been found to run through the Spermaphyta.

Equisetum. The sequence of cell divisions accompanying the development of the leaf in Equisetum is shown in the accompanying figure, which is reproduced from Sachs's 'Lehrbuch' (Fig. 273, first edition; Fig. 279 a, second edition). A careful scrutiny of this illustration brings to light the fact that the development of the successive segments cut off from the same side of the apical cell follows a different course in alternate segments. In one rapid divisions take place in an anticlinal and a periclinal direction which soon result in the production of a slight bulge (see the point marked $b$ on the right-hand side of the figure). In the segment next above, after the first anticlinal divisions have occurred, development for the time being comes to a stand. It is further evident from the drawing that a leaf is developed from each of the rapidly dividing segments, and that the whole product of one such segment (i. e. the cell group between any two segments which after one or two divisions remain for a time quiescent) takes part in its formation. As the cells forming the bulge or leaf primordium undergo further division, one of their number situated at the apex takes on the functions of an apical cell, and it is by the segmentation of this cell that the elongation of the leaf in an upward direction is continued. The cells forming the lower part of the bulge, i. e. the residual cells derived from the same original segment, also continue to divide and furnish the surface layer of the lengthening internode (see cells marked $r$ ). At a much later period one of the group of cells (marked $i$ ) derived from the alternate primary segment 
resumes activity, and gives rise to a new apical cell.which divides to produce the axillary bud. Thus, in the envelopment of the internode with a leafskin through the extension below the node level of the lowermost cells of the leaf primordium, the scheme of leaf development in Equisetum is wholly comparable with that described above for a Spermophyte. In both, these extensions cover and are fused with the internode below the node at which the leaf separates from the axis, and keep pace with the elongation of the enclosed core. Equisetum is the type which Hofmeister

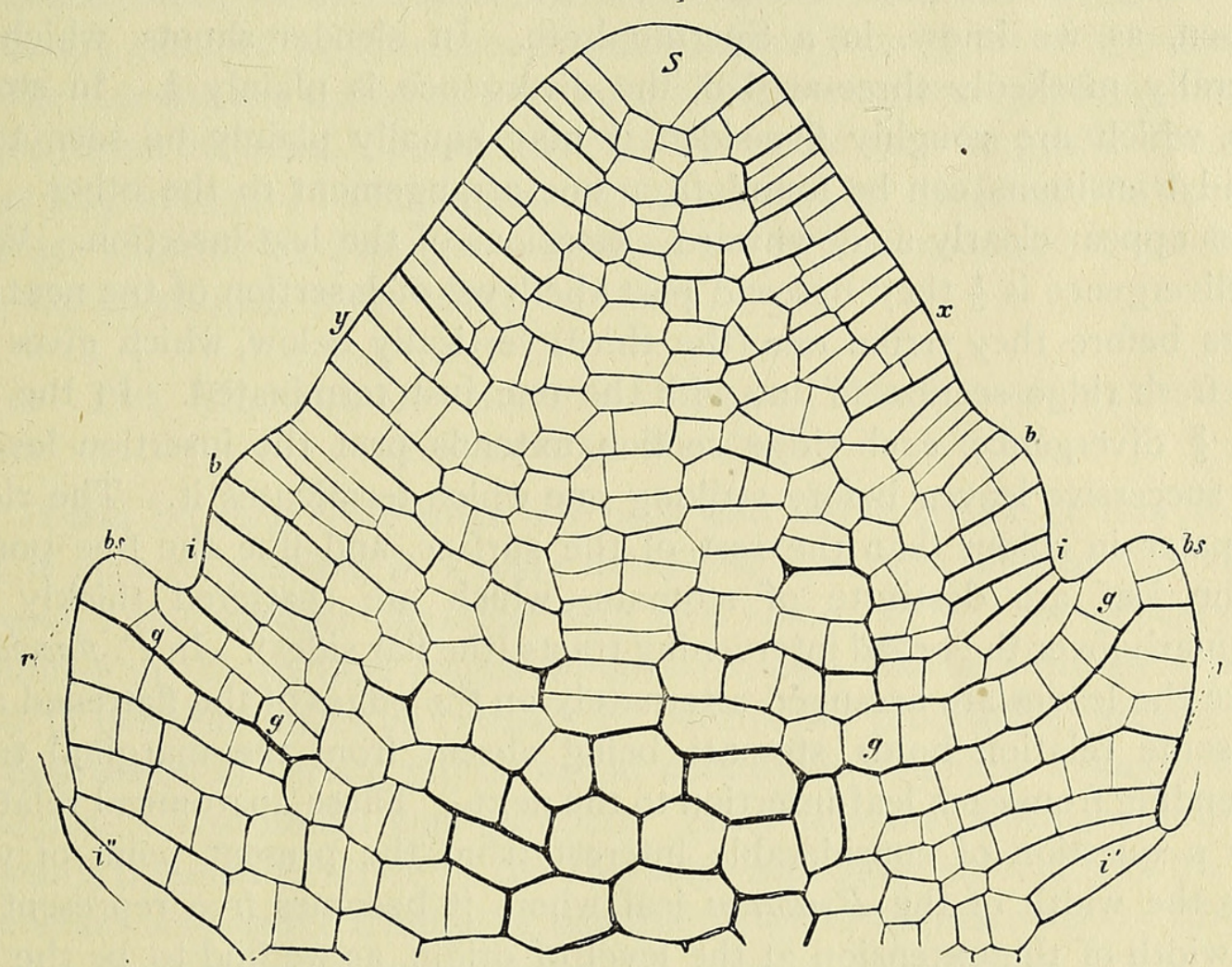

FIG. 34. Longitudinal section through the stem apex of Equisetum telmateia (reproduced from Sachs's 'Lehrbuch', Ist ed., p. 336). $x, y$ indicate the highest, youngest rudiment of an annular swelling which will develop into a leaf-sheath; $b, b$, the same older; $b s$, apical cells of a still older leaf-rudiment; $g$, rows of cells from which the vascular bundles are derived; $i$, the lowest layers of cells of the segments $;^{1} r$, the rudiment of the cortex of the internode; $s$, apical cell of stem.

takes in illustration of that Berindung of the stem which, he considered, probably occurs in all leaf-bearing plants from Chara upwards. He was, however, unable to furnish evidence in support either of this general pronouncement or of the more definite statement that the stem is represented by the pith alone and that all the tissue external to it is to be regarded as foliar in character, and based his view on phylogenetic considerations and grounds of general probability. ${ }^{2}$

1 It is of interest to note in the present connexion that in the legend accompanying this figure in both the first and second editions it is stated of the cells indicated by the letter ' $i$ ' that they take no part in the formation of the leaves, but that in the legend to the same figure in De Bary's Vergleichende Anatomie this sentence does not appear.

2 See Flora, 1863 , p. I 73 . 
Tmesipteris and Psilotum. In Tmesipteris and Psilotum the appendages of the stem are by general consent regarded as leaves, and in both genera they have been described as decurrent. ${ }^{1}$ In Tmesipteris they are obviously so, and the envelopment of the axis is as self-evident here as in many of the Conifers. In Psilotum the very minute subulate leaves are seated on the ridges of the angled stem and their insertion occupies an insignificant fraction of the circumference in the adult axis. They are composed of epidermal and cortical tissue and contain no vascular strand. In $P$. triquetrum they are spirally arranged, though the divergence varies, as may happen, as we know, in a Spermophyte. In slender shoots, which are generally markedly three-angled, the divergence is plainly $\frac{1}{3}$. In stouter axes, which are roughly five-sided, it may equally plainly be seen to be $\frac{2}{5}$, and transitions can be found from one arrangement to the other. The ridges appear clearly as downward extensions of the leaf-insertion. When the divergence is $\frac{1}{3}$ they descend past the level of insertion of the next two leaves before they strike one (the third) vertically below, which gives rise to a fresh ridge section in line with the one just terminated. In the case of a $\frac{2}{5}$ divergence, each ridge section extends past the insertion level of four successive leaves before striking one which terminates it. The ridges are paler in colour than the rest of the surface, and like the free portion of the leaf are destitute of stomata, which are scattered thickly and irregularly over the broad intervening tracts (the flat sides). In P. flaccidum, where the leaves are arranged alternately on the edges of the flattened axis, the same relation holds, stomata being absent from the marginal tracts descending from each leaf-insertion to the next. These anatomical relations raise a question of considerable interest from the present point of view. Does the width of the Psilotum leaf where it becomes free represent the real width of the extension at the level of origin, as we find to be the case in the higher plants, however small the free portion of the leaf may be (see, e.g., Fig. 3I), or are the free structures much-contracted tips, the downward extensions of which are nevertheless broad enough to meet and unite laterally? In other words, do we see here a surface which is only partially foliar in character, a condition which so far as appears does not occur in the Spermophyta, or have we to suppose that a contact line runs down the middle of the stomata-bearing tract, passing now between and now through stomata indiscriminately, and that the fusion is so complete (or deep) as to leave no visible trace? Among Spermophytes it is rare to find the insertions so small in proportion to the whole circumference that those belonging to the several leaves in one cycle of the spiral, if aligned at one level, would obviously not meet round the axis, but the succulent stems of Senecio articulatus and S. anteuphorbium furnish cases in point.

1 See A. P. W. Thomas, Proc. Roy. Soc., vol. lxix, p. 349, 1902, and G. M. Sykes, Ann. Bot., vol. xxii, p. 73, 1908 . 


\section{Anatomico-physiological Relations in the Spermophyte Shoot. I6 I}

The circumference of the axis here is often far too great to be encircled in this way by the leaf-bases. But we find contour lines starting from the insertion which spread out sideways far enough to meet those descending from neighbouring insertions, so that it becomes evident that the width of insertion cannot be taken as an invariable guide to the width of the descending extension since a sharp contraction may occur at the node. These contour lines in Senecio as well as the line from the midrib are free from stomata which are scattered thickly over the intervening areas. On the other hand, in the succulent stem of Euphorbia pendula, where the leaves are reduced to non-vascular scales, there is no trace of a fusion line, and the stomata are scattered round the whole circumference, midrib line and line of fusion included. From these facts it would then be possible to argue either way in regard to the appearance presented by Psilotum, but the clear evidence afforded by Tmesipteris inclines one to the view that an enveloping leaf-skin exists also in the related genus. ${ }^{1}$

\section{The Bearing of the 'LeAF-Skin' THeory on CERTAIN Genetical Problems.}

It will be clear from what has been said in the course of this account that it may be possible in a plant exhibiting a varying degree of hairiness to resolve this variable character into two components: one primary (i.e. exhibited in the earliest stages of development), constant (up to a point), fixed in position, inherited (subject to permissive conditions), because it is the expression of certain physiological conditions definitely associated with a particular anatomical configuration. Since the anatomical contours are constant, the manifestation of the character especially associated with them is constant also under a range of conditions, wider or narrower for different types and not at present capable of precise formulation. The other, adventitious, appreciably inconstant in degree, variable in position, not inherited, representing a secondary effect superposed upon the primary, a response in areas still plastic enough to respond to conditions set up at a later stage in development, and causing a flooding effect which may lead to blurring or obliteration of the inherited feature. This secondary effect is of common occurrence in the flowering region of many plants which are more or less free from hairs in the vegetative region. The production of flowers and small bracts in place of much larger foliage leaves must involve a considerable physiological readjustment, and may well be a prime cause of the general condition of hairiness which often sets in at this point.

We are in the habit of classifying the characters of organisms under the head of those which are inherited and those which are not, although

1 The early divisions of the daughter segments of the apical cell in Psilotum have been followed for some distance by Solms-Laubach, but the origin of the leaf rudiment is not shown (see Ann. du Jardin botanique de Bnitenzorg, vol. iv, 1884). 
recognizing that these categories are not sharply divided, for it is evident that inheritance of some characters does not take place in equal measure in different types. The hairy character affords a case in point. The conditions which lead to general hairiness in the vegetative shoot of such a form as Matthiola incana prevail throughout this region and throughout the plant's life, and with such uniformity that we can detect no difference between individuals. We have here an example of strict or constant inheritance. In other instances, such as some of those described above, in which the hairiness is localized, the constitution of all the individuals of the species may be alike in regard to potentiality for hair production, so that if the appropriate conditions are maintained the hairy character is always exhibited in an expected manner. But it may frequently happen that this is not the case. We have then what we may describe as conditional inheritance. The character may not be manifested, but if it is, it will appear in due order in relation to the general development, as is well seen e.g. in Asclepias linifolia, where the physiological condition existing in a lateral axis may be sufficiently different from that in the main axis for a conspicuous hair line to be formed in the one case while it is absent in the other. But in another type a more general state of plasticity may exist, so that a further development of hairs may occur without a definite time or place relation. The character then ranks among those which are fluctuating or non-inherited. With fuller knowledge classification in this manner may become unnecessary, but in the meantime the use of some terminology such as that here adopted, which indicates these distinctions, is convenient.

From this point of view anthocyanin production in the vegetative shoot may be classed with hair formation. Localization of the colouring matter in a particular tissue or layer can be observed in many species. Where there is inheritance of the 'constant' type we should expect this, though an overflow beyond these limits might be anticipated under favourable conditions. In Lobelia fulgens, where the inheritance appears to be 'constant', the pigment is confined to the epidermis and perhaps a cell here and there in the first hypodermal layer. Although present in such quantity as to produce a very deep coloration it is absent from the unicellular hairs (see foot-note to p. I54). On the other hand, in Lopezia coronata, where also the anthocyanin occurs in the epidermis, the hairs are coloured as well. In other cases, as in the uniformly coloured stem of a red-stemmed Dracaena, the pigment is present in the first hypodermal layer and is absent from the epidermis. Though in a particular species the potentiality for anthocyanin production may be constantly exhibited in a particular cell layer, an alteration in physiological equilibrium arising from internal causes may lead to the appearance of the pigment elsewhere. Thus in the hypocotyl of Antirrhinum Orontium a slight amount of 


\section{Anatomico-physiological Relations in the Spermophyte Shoot. I63}

anthocyanin is usually present in the innermost layer of the cortex, and also, though to a less extent, in the outermost layer, the intervening layers and the epidermis being colourless. Now in this species adventitious buds, from one to three or four in number, are frequently formed in the lower region of the hypocotyl and develop into branches. These buds are exogenous in origin and are derived from the epidermis and first hypodermal layer (see Figs. 28 and 29). In a hypocotyl containing so little anthocyanin that outwardly it appeared green these buds, even when sufficiently developed to show two divergent lobes representing the first leaf-pair, may nevertheless be coloured a deep red in every cell, thus presenting a striking contrast with the axis on which they are borne. Here a general flooding of the whole embryonic structure has taken place under altered physiological conditions. In passing it may be noted that the presence of adventitious buds on the hypocotyl has now to be viewed from the point of view of the development, normally and not as the result of mutilation or other injury, of a branch from foliar tissue, which furthermore shows no differentiation in the way of affording fixed points for their origin. For there seems no reason to doubt, especially in view of the uniform degree of hairiness displayed from the cotyledon node to the 'collar', that the cotyledon skin is coextensive here, as elsewhere, with the hypocotyl axis. What is the immediate cause of these outgrowths which have no definite relation to the general anatomical configuration-the entering trace joins on anywhere to the inner face of a secondary xylem bundle by curving to one side (see Fig. 29) - is not self-evident. Possibly a clue may be found in the relation between the amount of parenchymatous and vascular tissue present in the axis. In the diarch root of Antirrhinum the primary xylem is extremely scanty in amount, there being only two or three small vessels at each pole. Secondary thickening sets in so early that it is a matter of considerable difficulty to obtain a section of a root in which secondary increase has not yet begun. The secondary xylem forms a solid core and is considerable in amount in proportion to the bulk of the root. In the hypocotyl also there is proportionately little parenchyma (generally two layers or at most three besides the bundle sheath), so that it remains extremely slender in spite of its considerable length. It is conceivable that these adventitious buds result from some extreme condition (? of tension) set up in the hypocotyl, which, where a larger bulk of parenchymatous tissue is present which can act as an absorber, or where the cotyledons or epicotyl grows more rapidly, becomes distributed or adjusted without the production of adventitious outgrowths.

\section{SumMARY OF CONCLUSions.}

I. The surface tissue of the Spermophyte shoot axis is of foliar origin, that is to say, the leaves are decurrent not only in those types in which 
they obviously appear to be so, but generally and probably universally throughout the group. This appears to be the case also in some at least of the Pteridophyta.

2. In those species in which a hypocotyl is developed, its superficial tissues are similarly derived from the cotyledons, and it is therefore to the cotyledons that we must look for an explanation of its external features.

3. This 'leaf-skin' is formed by a downward growth and extension of the leaf primordium, which keeps pace with the extension of the central axis with which it is fused, after the manner conceived by Hofmeister, who, however, in his Berindung theory goes so far (in the case of Equisetum specifically, and it would appear in the higher plants too) as to refer all the tissue external to the pith to the leaf.

4. The contact edges of these extensions may be so adjusted or so deeply fused as to show no outward trace. Or they may exhibit the characteristics of potential edges and be demarcated in various ways (by ridges, furrows, lines of hairs or of colour).

5. When each leaf-insertion completely encircles the stem (as in most Monocotyledons and a few Dicotyledons), or when the leaves, being opposite or whorled, come into iateral contact at the level of insertion (as in many Dicotyledons and some Conifers), the downward extension of each leaf is limited to a single internode.

6. Where the leaves are opposite, but where the insertion width occupies less than $\frac{1}{2}$ the circumference of the stem (especially well seen in some Dicotyledons with four-angled stems), the leaf-extension stretches through two internodes.

7. Where the leaves are spirally arranged with an insertion width less than the circumference of the stem, the pattern traced by the fused edges of the extensions and the number of internodes through which the extension of any one leaf descends will depend on the leaf-divergence and the leafinsertion width.

8. If the leaf-divergence and the leaf-insertion width are expressed by the same fraction $\left(\right.$ e.g. $\left.\frac{2}{5}\right)$, the contact line descending from one edge of each insertion will 'pick up', and the one from the other will 'be picked up' by a corresponding line descending from the neighbouring leaf below and above respectively, and each fusion line thus formed will extend downwards until it terminates in the axil of a particular leaf in the cycle.

9. When the leaf-insertion width occupies some lesser fraction of the circumference no 'pick-up' occurs; the boundary lines run a separate course, and hence two terminate in each axil, one on either side the mid-point.

I0. In the circumstances described under (8) and (9) the boundary line from one edge of the leaf-insertion extends through a greater number of internodes than the one from the other edge of the same insertion. 


\section{Anatomico-physiological Relations in the Spermophyte Shoot. 165}

I1. The length of axis traversed by the separate leaf-trace, though constant within narrow limits for the species, bears no direct relation to the limits of the leaf area laid down in the superficial tissue of the axis. Hence it may be said that the delimitation of an inner boundary to this region of the leaf is a question solely of definition, but that on the outer surface this boundary, in many types, has a real existence capable of demonstration.

I2. Two forms of the surface pattern are met with, having the relation of mirror images, the individual or axis exhibiting the one or the other according as its general orientation is from right to left or from left to right.

I3. If the leaf-insertion width is such that the insertions of all the leaves in one cycle of the spiral are together just equal to the circumference of the stem (e.g. $\frac{1}{5}$ in a $\frac{2}{5}$ spiral or $\frac{1}{8}$ in a $\frac{3}{8}$ spiral), the demarcations of the extensions will appear as continuous lines along the length of the axis.

I4. In the case of flowering stems the leaf-skin is formed by the bracts (when present) and the outermost sepals.

I5. The demarcation of leaf and cotyledon extensions by lines of hairs only occurs (so far as observed) when the basal free margins of leaves and cotyledons are furnished with hairs.

16. Demarcation of the boundaries of the leaf-extensions by lines of hairs is a character showing what may be termed conditional inheritance, in contradistinction to the type of inheritance which is (approximately) constant under all conditions.

17. A further fluctuating development of hairs in response to altered conditions may result in a general flooding of the surface, thus blurring the effect of the hereditary component. A similar secondary effect may be observed under appropriate conditions when the contours are traced out in anthocyanin.

I8. The occurrence of adventitious exogenously formed buds on the hypocotyl (as e.g. in Antirrhinum Orontium) appears to show that a shoot can be formed directly from foliar tissue at undifferentiated points without previous mutilation or other injury.

19. Such buds may show a general flooding with anthocyanin in response to the different conditions existing in the embryonic tissue, while the parent axis has the colouring matter localized in a definite region.

In conclusion I wish to express my grateful thanks to Miss Margaret Willis, who made the drawings here reproduced. I have also to thank Herr W. Engelmann of Leipzig for his courtesy in allowing me to reproduce the two figures taken from Sachs's 'Lehrbuch' and the 'Vorlesungen '.

The expenses incurred in connexion with this work have been defrayed in part by grants from the Royal Society and from the British Association for the Advancement of Science. 


\section{$2 \mathrm{BHL}$ Biodiversity Heritage Library}

Saunders, Edith R. 1922. "The leaf-skin theory of the stem: a consideration of certain anatomico-physiological relations in the spermophyte shoot." Annals of botany 36, 135-165. https://doi.org/10.1093/oxfordjournals.aob.a089790.

View This Item Online: https://www.biodiversitylibrary.org/item/234428

DOI: https://doi.org/10.1093/oxfordjournals.aob.a089790

Permalink: https://www.biodiversitylibrary.org/partpdf/319033

\section{Holding Institution}

Smithsonian Libraries

\section{Sponsored by}

Biodiversity Heritage Library

\section{Copyright \& Reuse}

Copyright Status: Not in copyright. The BHL knows of no copyright restrictions on this item.

This document was created from content at the Biodiversity Heritage Library, the world's largest open access digital library for biodiversity literature and archives. Visit BHL at https://www.biodiversitylibrary.org. 